\title{
Cooperativas de catadores em São José dos Campos: infraestrutura, perfil socioeconômico e saúde
}

A coleta seletiva e a reciclagem são atividades que contribuem para a sustentabilidade urbana, redução de impactos deletérios ao meio ambiente, economia do uso de recursos naturais e prolongamento da vida útil dos aterros sanitários. No território brasileiro, essa atividade ocorre com a participação de catadores, que atuam de forma autônoma ou associada. As políticas públicas voltadas à inclusão desses trabalhadores no manejo dos resíduos sólidos visam garantir não somente a geração de trabalho e renda, mas também a inclusão social e econômica dos mesmos. Em São José dos Campos, assim como na maioria dos municípios brasileiros, o trabalho realizado pelos catadores não foi (re) conhecido pelo poder público por longo período. Em vista disso, o presente trabalho foi realizado com o objetivo de identificar a infraestrutura das cooperativas atuantes, avaliar o perfil socioeconômicos dos seus membros, a situação clínico-odontológica e os índices de depressão dos catadores cooperados. Para execução do projeto, foi realizado um estudo de caso descritivo com análises mistas e se obteve dados quantiqualitativos por meio de entrevistas subsidiadas por questionários estruturados, aplicados pela equipe do projeto com os gestores e trabalhadores das cooperativas. Também foram utilizados os testes Oral Heath Impact Profile e Self-Report-Questionnaire, para anamnese odontológica e índices de depressão, respectivamente. Dentre os resultados obtidos ressalta-se a necessidade de apoio do Poder Público Municipal para potencialização dos serviços prestados pelas cooperativas. As três cooperativas atuantes no território joseense se encontram em estágios distintos no que se refere à infraestrutura e geração de renda. A cooperativa Futura, que recebe maior apoio municipal se encontra em melhor situação operacional. A cooperativa São Vicente, mesmo sendo a mais antiga do município, ainda carece de parceiros e infraestrutura adequada. A menor cooperativa do município em relação à renda, número de cooperados e infraestrutura (CooperAlfa) é também a mais nova e que realizou a maior inclusão de ex-catadores autônomos.

Palavras-chave: Cooperativas; São José dos Campos; Resíduos Sólidos.

\section{Collectors' cooperatives in São José dos Campos: infrastructure, socioeconomic profile and health}

\begin{abstract}
Selective collection and recycling are activities that contribute to urban sustainability, reduction of deleterious impacts to the environment, savings in the use of natural resources and prolonging the useful life of landfills. In Brazil, this activity occurs with the participation of scavengers, who act in an autonomous or associated way. Public policies aimed at including these workers in the management of solid waste aim not only to ensure the generation of work and income, but also their social and economic inclusion. In São José dos Campos, as in most Brazilian municipalities, the work done by the collectors was not (re) known by the public authority for a long period. In view of this, the present work was carried out with the objective of identifying the infrastructure of the active cooperatives, evaluating the socioeconomic profile of their members, the clinical-odontological situation and the depression rates of the cooperating collectors. To carry out the project, a descriptive case study was carried out with mixed analyzes and quantitative-qualitative data were obtained through interviews structured by structured questionnaires, applied by the project team with the managers and workers of the cooperatives. Oral Heath Impact Profile and Self-Report-Questionnaire were also used for dental anamnesis and depression indexes, respectively. Among the results obtained, it is worth mentioning the need for support from the Municipal Public Power to increase the services provided by the cooperatives. The three cooperatives operating in the Jose's territory are in distinct stages in terms of infrastructure and income generation. The Futura cooperative, which receives more municipal support, is in a better operational situation. The São Vicente cooperative, although it is the oldest in the municipality, still lacks partners and adequate infrastructure. The smallest cooperative in the municipality in relation to income, number of cooperatives and infrastructure (CooperAlfa) is also the youngest and has carried out the largest inclusion of former self-employed scavengers.
\end{abstract}

Keywords: Cooperatives; São José dos Campos; Solid Waste.

Topic: Engenharia Ambiental

Reviewed anonymously in the process of blind peer.

\section{Fabiana Alves Fiore}

Universidade Estadual Paulista Júlio Mesquita Filho, Brasil http://lattes.cnpq.br/9905539715619645

fabiana.fiore@ict.unesp.br

Erika Homem de Melo Sanchez

Universidade Estadual Paulista Júlio Mesquita Filho, Brasil http://lattes.cnpq.br/6015770954195537

erikahms1@gmail.com

\section{Symone Cristina Teixeira}

Universidade Estadual Paulista Júlio Mesquita Filho, Brasil http://lattes.cnpq.br/1728462753516751

symone@fosjc.unesp.br

6

DOI: 10.6008/SPC2318-2881.2017.001.0003
Received: 18/02/2017

Approved: 20/05/2017

\section{Referencing this:}

FIORE, F. A.; SANCHEZ, E. H. M.; TEIXEIRA, S. C.. Cooperativas de catadores em São José dos Campos: infraestrutura, perfil socioeconômico e saúde. Nature and Conservation, v.10, n.1, p.26-38, 2017. DOI: http://doi.org/10.6008/SPC2318-2881.2017.001.0003 


\section{INTRODUÇÃO}

O desenvolvimento econômico e tecnológico, o crescimento populacional, e a urbanização, trazem aumento na produção de resíduos sólidos urbanos (RSU), tanto em quantidade como em diversidade, principalmente nos grandes centros urbanos (GOUVEIA, 2008). No Brasil, são geradas mais de 200 mil toneladas por dia RSU e estima-se que destes mais de $30 \%$ são de materiais recicláveis. A região sudeste possui a maior geração e coleta per capita de RSU do país. (IPEA, 2012; ABRELPE, 2013; SNIS, 2014).

A Política Nacional de Resíduos Sólidos (PNRS), instituída no Brasil através da Lei 12.305/10, estabelece em suas diretrizes o reconhecimento dos resíduos sólidos como bem econômico de valor social e gerador de serviço, assim como a integração dos catadores de materiais recicláveis no sistema de coleta seletiva de modo que seja realizada a sua inclusão social e econômica. Estabelece também a necessidade de minimização da geração de RSU, assim como o tratamento e a destinação final adequada dos rejeitos (BRASIL, 2010).

A coleta seletiva de RSU pode ser realizada porta a porta pela prefeitura, ou por empresas terceirizadas em pontos de entrega voluntária espalhados pelos municípios, ou até mesmo por catadores autônomos de materiais recicláveis e suas associações formais. (ABRELPE, 2014) traz dados afirmando que 83\% dos municípios brasileiros não possuem sistema de coleta seletiva. SNIS (2014) evidencia que apenas 40,6\% dos municípios não realizam este tipo de coleta.

Em 2008, o IBGE identificou a existência 1.175 cooperativas e associações de catadores que reuniam cerca de 30.390 catadores no Brasil. Identificou também outros 40.059 catadores de resíduos sólidos nas áreas urbanas do território, atuando de forma autônoma. Em 2012 o número de catadores, associados às cooperativas ou não, saltou para 1.426 .584 , se considerada a declaração associada às residências com a presença de catadores (IPEA, 2012). As cooperativas de catadores são responsáveis por 32,7\% da massa de materiais recicláveis coletados no Brasil (SNIS, 2015). No estado de São Paulo, o número de catadores estava entre 79.770 e 279.383. Dos cerca de 80.000 que se declaram catadores, aproximadamente $68 \%$ são do sexo masculino e 54\% são negros ou pardos que residem prioritariamente em áreas urbanas (97\%) (IPEA, 2012).

A renda média mensal declarada pelos catadores do Estado de São Paulo é 30\% superior ao salário mínimo nacional, no entanto, pouco mais da metade deles realizam contribuição previdenciária. Cerca de $13 \%$ desses catadores são analfabetos, $27 \%$ completaram o ensino fundamental e $13 \%$ completaram o ensino médio (IPEA, 2012). O Plano Estadual de Resíduos Sólidos (PERS/SP), lançado em 2014, traz poucas informações primárias sobre os catadores atuantes no estado.

Composta por 39 municípios, a Região Metropolitana do Vale do Paraíba Paulista gerou, em 2013, 2.091ton/dia de RSU. São José dos Campos é município com maior área territorial, população e Produto Interno Bruto (PIB) desta região. O município também apresenta Índice de Desenvolvimento Humano (IDH 0,807) superior ao do Brasil (CETESB, 2013; IBGE, 2010). Caracterizado por sua intensa atividade industrial e tecnológica, o município implantou coleta seletiva porta a porta a mais de 30 anos e segundo a Prefeitura de São José dos Campos, abrange 100\% de seu território. 
Em São José dos Campos, os resíduos recicláveis coletados porta a porta são encaminhados para triagem dentro da área do aterro sanitário municipal, por agentes sociais empregados formalmente pela Urbanizadora Municipal (URBAM), que coletaram 30.270,20ton de materiais recicláveis em 2013, segundo a Urbam. De acordo com dados do Plano Municipal de Gestão Integrada de Resíduos Sólidos (PMGIRS), elaborado pelo município em 2015 , a coleta seletiva recolheu uma massa de recicláveis de cerca de $8,6 \%$ do total dos RSU gerados pela população; além disso, após segregação, cerca de $40 \%$ desses materiais ainda foram encaminhados ao aterro sanitário municipal como rejeito.

Além do expressivo número de catadores autônomos presentes nas vias públicas, atuam em São José dos Campos três cooperativas formais de catadores: Futura, São Vicente e CooperAlfa, que também realizam a coleta, triagem e venda de materiais recicláveis. A escassez de dados públicos relativos às cooperativas e catadores autônomos no município, o anseio por apoiar as atividades das associações formais de catadores em conjunto com a incumbência expressa na Política Nacional de Resíduos Sólidos, foram os propulsores da realização deste projeto que teve como principais objetivos:

a) a obtenção de dados primários da situação socioeconômica dos catadores de materiais reutilizáveis e recicláveis atuantes nas cooperativas;

b) a verificação da infraestrutura existente nas cooperativas;

c) a identificação de sugestões dos gestores para a potencialização das atividades;

d) a realização de anamnese odontológica, com identificação dos tratamentos necessários de periodontia, dentística, prótese total ou parcial, endodontia e exodontia; e

e) a identificação do estado de sofrimento mental dos cooperados.

\section{METODOLOGIA}

O projeto é um estudo de caso descritivo com análises quanti-qualitativas. Os dados da infraestrutura das cooperativas e da situação socioeconômica de seus cooperados foram obtidos por meio de entrevistas diretas com os gestores dessas associações e com os seus cooperados, respectivamente. Os questionários estruturados elaborados foram elaborados pela equipe do projeto e validados pelas secretarias municipais de meio ambiente e de serviços sociais. As entrevistas foram conduzidas exclusivamente pela equipe do projeto, durante o mês de junho de 2015, nas áreas das cooperativas. Os dados coletados foram sistematizados com auxílio de planilhas eletrônicas, através das quais foram computadas médias simples e percentuais para análise.

Tabela 1: critério de verificação do SRQ-20.

\begin{tabular}{c|c}
\hline Critério & Resultado \\
\hline$\sum$ Respostas "sim" $\geq 7$ & O entrevistado possui índices de depressão \\
\hline$\sum$ Respostas "sim" $<7$ & O entrevistado não possui indicativo de depressão \\
\hline
\end{tabular}

Para a realização da anamnese foi utilizado o questionário Self-Report-Questionnaire (SRQ-20), que avalia o estado de sofrimento mental do entrevistado. De acordo com Jacarandá (2008), o SRQ-20 é um instrumento confiável e validado para tal verificação. O questionário é de fácil entendimento com apenas duas opções de respostas, sim ou não. Contem 20 questões. Em sua análise padronização o número de 
respostas positivas "Sim" é somado e os resultados superiores ou iguais a sete sugerem estado de depressão, conforme critério de verificação apresentado na tabela 1.

Na segunda parte da anamnese foi utilizado o questionário Oral Heath Impact Profile (OHIP-14), composto por 14 itens para avaliação do impacto das condições de saúde bucal na qualidade de vida dos indivíduos. As dimensões de impacto abrangidas por este teste são em relação aos últimos 6 meses: limitação funcional, dor física, desconforto psicológico, incapacidade física, incapacidade psicológica, incapacidade social e deficiência. As respostas são dadas através de uma escala codificada no seguinte padrão: 0 - nunca, 1 - raramente, 2 - às vezes, 3 - frequentemente e 4 - sempre. Cada pergunta possui um peso associado, conforme mostra a tabela 2. Ao final do questionário realiza-se a somatória das pontuações ponderadas pelos respectivos pesos definidos anteriormente. O impacto geral é determinado a partir dos critérios apresentados na tabela 3.

Tabela 2. Peso das questões do OHIP-14.

\begin{tabular}{|c|c|c|}
\hline \multicolumn{3}{|c|}{ Pergunta: Por causa dos seus dentes ou da sua boca... } \\
\hline Dimensão & Questão & Peso \\
\hline \multirow[t]{2}{*}{ Limitação funcional } & 1 - Você já teve problema para falar alguma palavra? & 0.51 \\
\hline & 2-Você sentiu que o sabor dos alimentos tem piorado? & 0.49 \\
\hline \multirow{2}{*}{ Dor fisica } & 3 - Você sentiu dores fortes em sua boca? & 0.34 \\
\hline & 4 - Você tem se sentido incomodado ao comer algum alimento? & 0.66 \\
\hline \multirow[t]{2}{*}{ Desconforto psicológico } & 5 - Você tem ficado pouco à vontade? & 0.45 \\
\hline & 6-Você se sentiu estressado? & 0.55 \\
\hline \multirow[t]{2}{*}{ Incapacidade fisica } & 7 - Sua alimentação tem sido prejudicada? & 0.52 \\
\hline & 8 - Você teve que parar suas refeiçòes? & 0.48 \\
\hline \multirow[t]{2}{*}{ Incapacidade pscicológica } & 9 - Você tem encontrado dificuldade em relaxar? & 0.60 \\
\hline & 10 - Você já se sentiu um pouco envergonhado? & 0.40 \\
\hline \multirow[t]{2}{*}{ Incapacidade social } & 11 - Você tem estado irritado com outras pessoas? & 0.62 \\
\hline & 12 - Você teve dificuldade em realizar suas atividades diárias? & 0.38 \\
\hline \multirow[t]{2}{*}{ Deficiência } & 13 - Você já sentiu que a vida em geral ficou pior? & 0.59 \\
\hline & 14 - Você tem estado sem poder fazer suas atividades diárias? & 0.41 \\
\hline
\end{tabular}

Tabela 3: critério de verificação do OHIP-14.

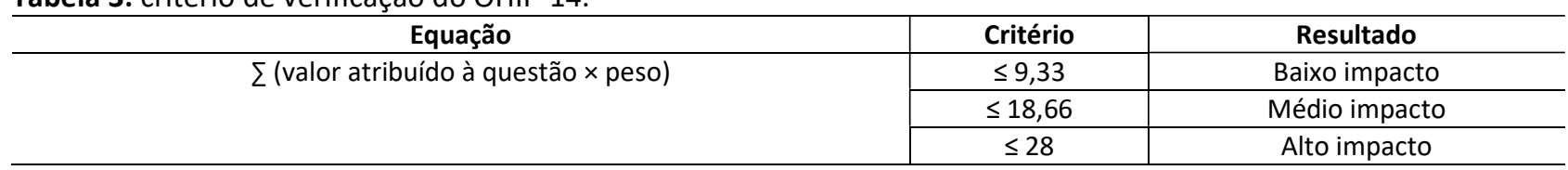

Após o levantamento dos dados de anamnese, foram realizados exames clínicos nos cooperados por profissional habilitado dentro de cada uma das cooperativas, visando ao reconhecimento dos problemas bucais e os tipos de tratamentos necessários. Também foram ministradas palestras de educação em saúde bucal, com orientação de escovação e passagem de fio dental correta e frequente, informações sobre doenças bucais e forma de evitá-las e entrega de kits odontológicos contendo pastas e escovas de dentes.

\section{RESULTADOS}

A cooperativa mais antiga do município, denominada São Vicente, está instalada em terreno de $5.000 \mathrm{~m}^{2}$ cedido pela igreja Mitra Diocesana na zona Leste do município, desde 2006. A cooperativa coleta os resíduos, utilizando 2 caminhões próprios, em órgãos públicos e empresas privadas, e recebe doações na 
própria cooperativa. Possui equipamentos básicos para segregação e beneficiamento dos materiais, tais como: prensas, balanças digitais e mesas de triagem feitas de madeira. Os equipamentos existentes são considerados insuficientes pelos gestores das cooperativas. A partir dos dados obtidos com os trabalhos de campo foi possível verificar que as três cooperativas do município de São José dos Campos possuem histórias, infraestruturas e focos distinto, conforme ilustrado pela figura 1.

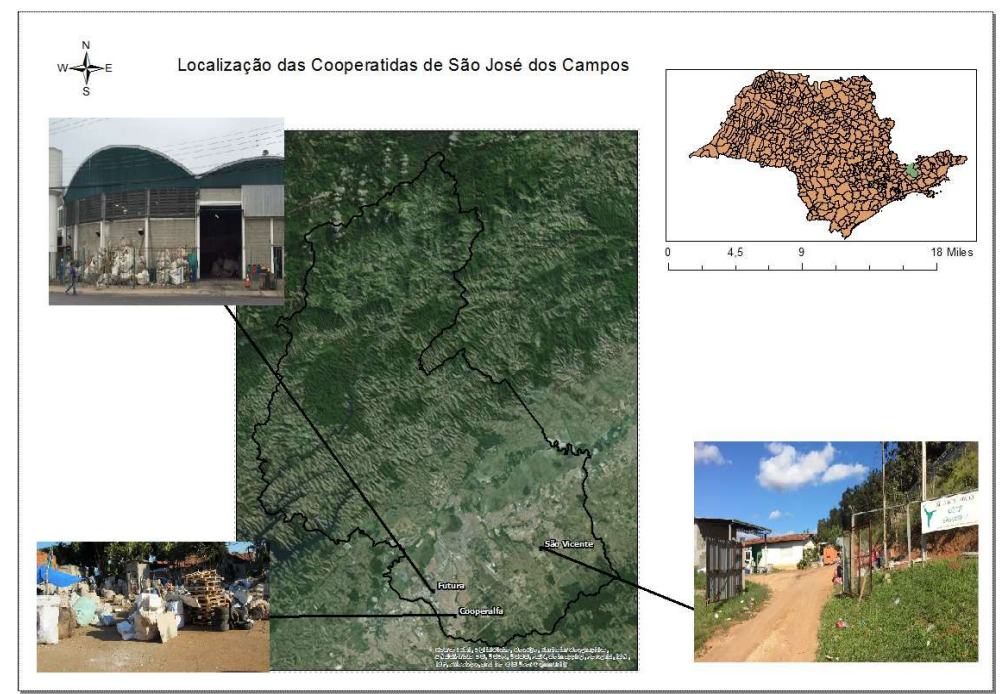

Figura 1: Localização das cooperativas de catadores de materiais recicláveis de São José dos Campos.

A cooperativa Futura foi fundada em 2006 e possui a melhor infraestrutura dentre as associações formais de catadores do município, com $700 \mathrm{~m}^{2}$ de área de galpão, a cooperativa possui equipamentos, tais como: esteira rolante, prensas e balanças que atendem à demanda de resíduos, segundo o seu gestor. 0 pagamento das contas de aluguel, água e energia elétrica são realizados pela Prefeitura de São José dos Campos. Os resíduos beneficiados pela cooperativa advêm de coletas realizadas pelos cooperados em pontos de entrega voluntária do município, em domicílios e empresas localizadas nas regiões sul e centro e das doações recebidas diretamente na cooperativa. O transporte dos materiais recicláveis é realizado por caminhões próprios.

A CooperAlfa iniciou suas atividades no início de 2015 em área de preservação permanente de recurso hídrico da Comunidade Menino Jesus, na zona sul da cidade, com apenas duas balanças e sem nenhum tipo de infraestrutura, equipamentos para triagem ou armazenamento de resíduos. A coleta dos materiais é realizada pelos próprios cooperados em carroças e kombis, nos comércios, empresas e na área central do município. Em 2016 a cooperativa foi realocada em terreno cedido pela prefeitura com área de $1.560 \mathrm{~m}^{2}$. Nesse local os membros da cooperativa improvisaram mesas para triagem dos materiais e espaço de descanso. Os equipamentos disponíveis na área da cooperativa se resumem a uma balança e um caminhão doado pela rede CataVale.

Com relação a infraestrutura todos os gestores consideram insuficientes as áreas dos galpões disponíveis para triagem. Destaca-se que a CooperAlfa não possui galpão e realiza a triagem dos resíduos a céu aberto, em solo não impermeabilizado e possui também uma pequena mesa de triagem improvisada 
com materiais obtidos em suas coleta, conforme se nota nas figuras $2 \mathrm{~A}$ e $2 \mathrm{~B}$. A Cooperativa São Vicente possui galpão sem adequada iluminação, ventilação, impermeabilização e cobertura.
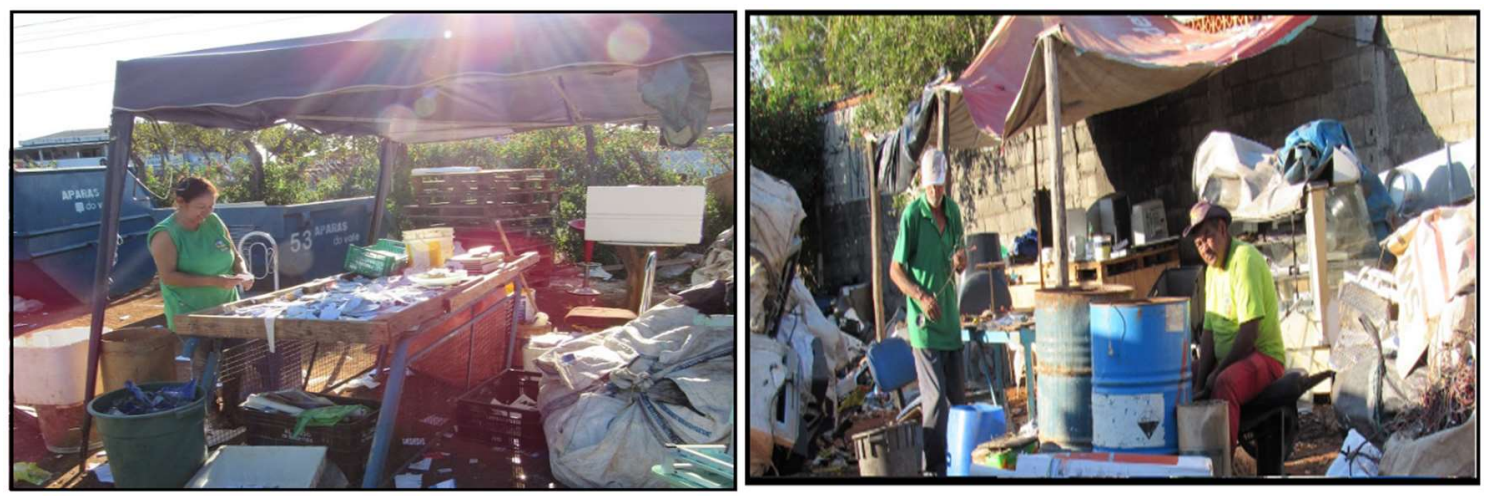

Figura 2: Triagem na CooperAlfa. A) Mesa de Triagem improvisada; B) Materiais sendo triados em solo não impermeabilizado.

A triagem é realizada em mesas estáticas de madeira, de acordo com as figuras 3A e 3B. 0 galpão de triagem da Cooperativa Futura é o mais bem equipado, possui esteira mecanizada, boa luminosidade, impermeabilização e cobertura, porém não possui ventilação satisfatória, como pode se observar na figura 4.
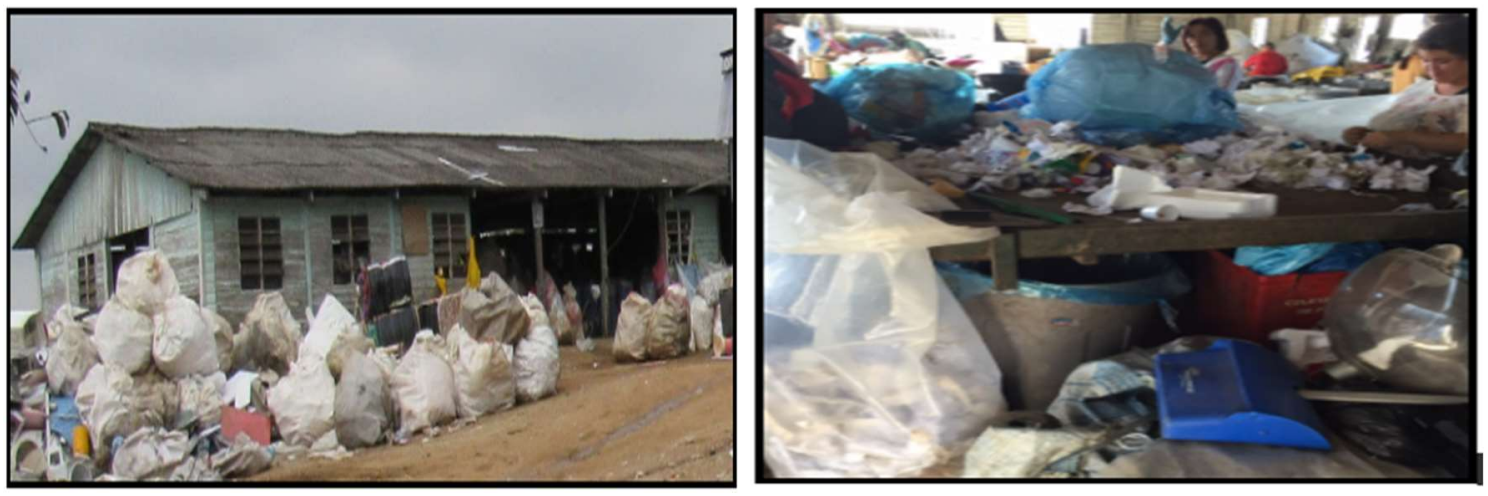

Figura 3: Cooperativa São Vicente. A) Galpão disponível para triagem; B) mesas de triagem.

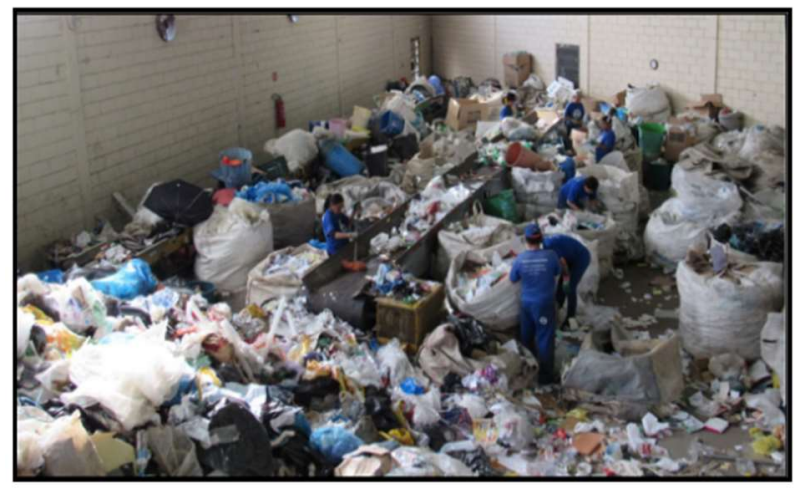

Figura 4: Área de triagem de resíduos com esteira rolante na cooperativa Futura.

A cooperativa São Vicente, possui a maior área entre as cooperativas e foi a única que considerou seu terreno suficiente para a demanda de resíduos recebidos e para a manobra de veículos. Os resíduos triados nas três cooperativas são dispostos em bags para posterior comercialização. Após prensagem na própria cooperativa, os resíduos são dispostos em solo não impermeabilizado na São Vicente e em caçambas 
na Cooperativa Futura, como mostrado nas figuras 5 e 6, respectivamente. A CooperAlfa não possui prensas, realiza o armazenamento dos materiais diretamente nos bags, que são dispostos em solo não impermeabilizado após a triagem, como mostrado na figura 7. Os rejeitos provenientes da triagem das 3 cooperativas são coletados pela Urbam e encaminhados para o aterro sanitário.

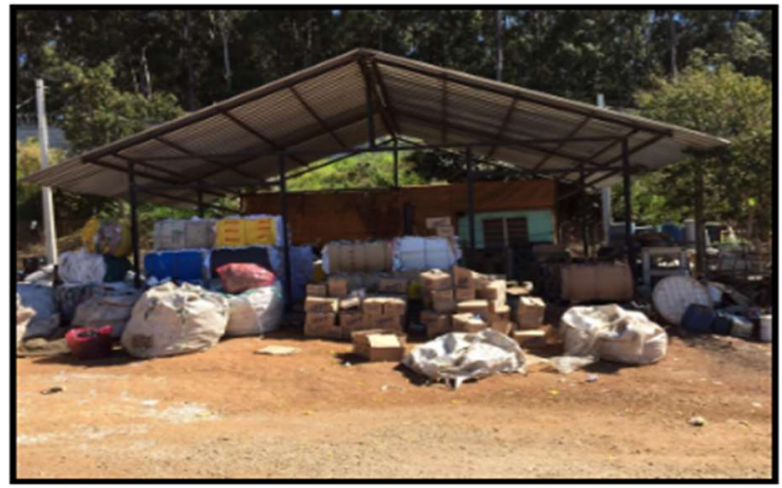

Figura 5: Materiais prensados e dispostos em solo não impermeabilizado e com cobertura parcial (Cooperativa São Vicente)

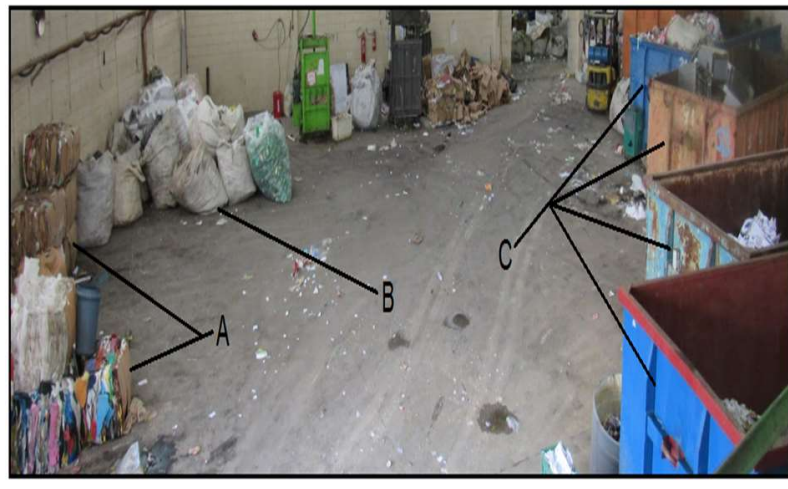

Figura 6: Área de disposição de resíduos em solo impermeabilizado. A) Materiais prensados; B) Materiais triados disposto em bags; C) Caçambas de armazenamento de materiais prensados.

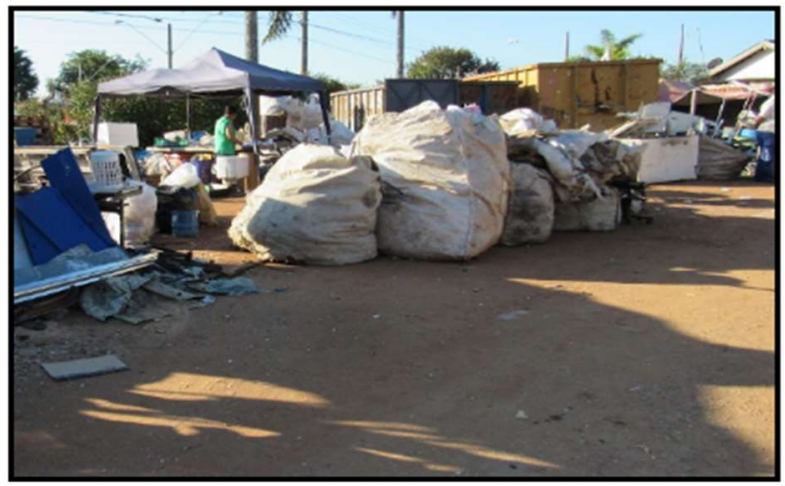

Figura 7: Materiais triados dispostos em bags em solo não impermeabilizado prontos para comercialização (CooperAlfa).

A Cooperativa Futura coleta em média 4,5ton de materiais recicláveis por dia, a Cooperativa São Vicente possui entrada diária de aproximadamente 1,5ton, enquanto a CooperAlfa coleta cerca de meia tonelada. Além de ser a cooperativa que tria a maior quantidade de resíduos, a Futura é a única que disponibiliza equipamentos de proteção individual (EPIs) e possui algum tipo de equipamento de proteção coletiva (EPC) em suas instalações. Mesmo com a ausência de EPIs e EPCs, nenhuma das cooperativas relatou 
a ocorrência de acidentes de trabalho. Nenhuma das cooperativas possui programa ou projeto de assistência de renda, cultura, alfabetização ou alimentação para os cooperados e suas famílias. O controle de despesas e receitas das cooperativas é realizado de forma diferenciada em cadernos, planilhas em papel e eletrônicas.

Para identificação da situação socioeconômica dos cooperados de São José dos Campos, foram entrevistados 19 dos 24 cooperados existentes na cooperativa São Vicente, 13 dos 20 cooperados da CooperAlfa e 57 dos 144 membros da Cooperativa Futura. Assim sendo, 47\% dos catadores formais atuantes no município foram abrangidos pela pesquisa.

A CooperAlfa é a única cooperativa com predominância de cooperados do sexo masculino (60\%), mas ainda assim não alcança os índices verificados pelo IPEA (2012) para o estado de São Paulo. Já as Cooperativas São Vicente e Futura possuem, respectivamente, 52,6\% e 68\% dos seus cooperados mulheres. A idade média dos cooperados associados às cooperativas em São José dos Campos varia entre 42,5 anos (cooperativa São Vicente), 40 anos na Cooperalfa e 38,5 anos na cooperativa Futura.

Na Cooperativa São Vicente 21\% dos cooperados são nascidos em São José do Campos na CooperAlfa esse percentual é de cerca de $30 \%$ e na cooperativa Futura $25 \%$ dos entrevistados são naturais do próprio município. A CooperAlfa é a cooperativa que incluiu o maior percentual de catadores autônomos no município - 53,8\% de seus membros. O percentual de inclusão de catadores autônomos nas cooperativas Futura e São Vicente são de 8,8 e 10,5\%, respectivamente. Quando inqueridos sobre a percepção de benefícios ao exercerem suas atividades em associações formais, todos os ex-catadores autônomos afirmaram ser mais beneficiados estando associados às cooperativas do que trabalhando de forma autônoma. Em relação ao grau de escolaridade dos cooperados, os principais resultados obtidos estão explícitos no Gráfico da Figura 8.

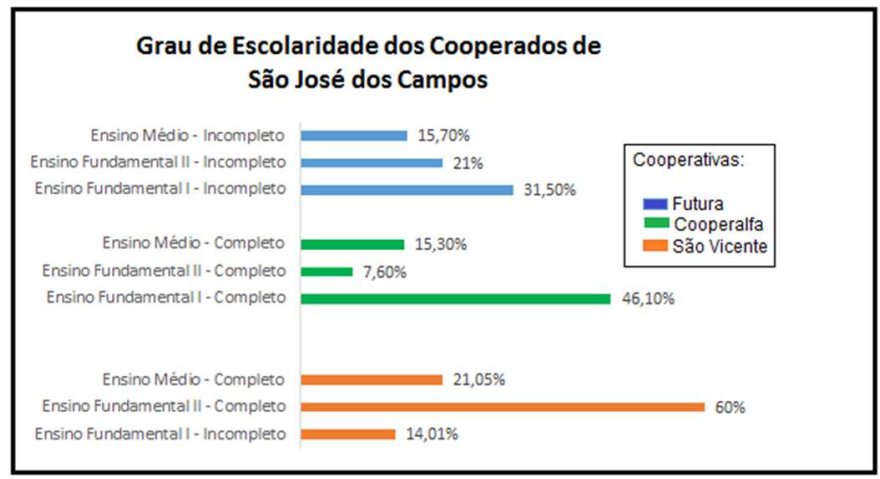

Figura 8: Grau de escolaridade dos cooperados de São José dos Campos.

85,4\% dos cooperados atuantes em cooperativas formais do município de São José dos Campos possuem filhos. Na Cooperativa São Vicente cerca de 10\% dos cooperados recebem recursos através do programa de transferência de renda do governo (Bolsa Família), na Cooperativa Futura 24,5\% dos cooperados recebem Bolsa Família ou Auxílio Aluguel e na CooperAlfa 23\% dos cooperados recebem Bolsa Família. A renda média dos cooperados varia de acordo com a cooperativa, sendo a Futura com maior renda média $(R \$ 800,00)$, São Vicente com a segunda maior $(R \$ 629,50)$ e CooperAlfa com renda média de $R \$ 346,15$. 
Nas Cooperativas São Vicente e CooperAlfa a maioria dos cooperados $(83,33 \%)$ vão a pé até o local de trabalho. Enquanto que na Cooperativa Futura $84,3 \%$ dos trabalhadores utilizam o transporte público. Entre os cooperados de São José dos Campos 37,6\% se declararam brancos, 25\% pardos, 11,36\% morenos, $14,7 \%$ negros e os $11,87 \%$ restante se declaram caboclos, escuros e indígenas. Para análise da percepção ambiental dos cooperados, inquiriu-se sobre a realização de segregação de resíduos recicláveis em suas próprias residências. Constatou-se que, mesmo trabalhando com a segregação de resíduos, $70 \%$ dos cooperados da CooperAlfa não a realizam em suas casas. A Cooperativa Futura e São Vicente apresentam porcentagens de catadores que não realizam separação iguais a $17,54 \%$ e $36,84 \%$, respectivamente. Todos os cooperados do município declararam que consideram importante, para o meio ambiente e para a sociedade, o trabalho que realizam.

Após a realização das anamneses com os trabalhadores das três cooperativas foi constatado que 89,47\% cooperados da São Vicente não vão ao dentista há mais de um ano e afirmam precisar de tratamento odontológico e 57,8\% sentirem vergonha por causa dos dentes. Na Cooperativa Futura $46 \%$ dos entrevistados declararam possuir condições de saúde bucal regular ou ruim. Esse resultado é preocupante, pois, segundo Barbieri et al. (2009), a saúde bucal afeta a vida social, a alimentação, as atividades de vida diária e o bemestar dos indivíduos.

Na cooperativa CooperAlfa 70\% dos trabalhadores sentem dores frequentes nos dentes e boca. Entre os cooperados $80 \%$ já se sentiram envergonhados por conta dos dentes ou da boca. O questionário de avaliação denominado OHIP - 14, que condiz com a auto percepção com relação à saúde bucal de cada indivíduo entrevistado, mostrou que apenas $6,4 \%$ dos indivíduos entrevistados identificam impacto em suas vidas sociais. Vale ressaltar que esse resultado evidencia que os cooperados possuem baixa percepção de sua região bucal.

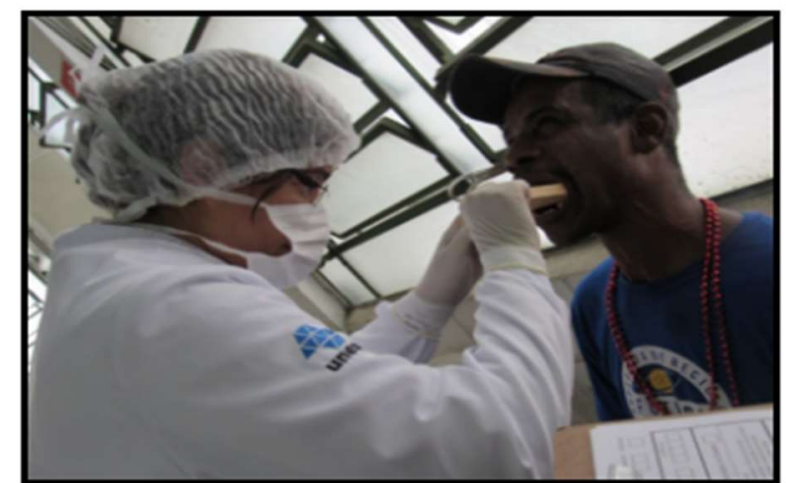

Figura 9: Exame clínico realizado em cooperado da Futura.

Após as visitas técnicas com os discentes e docentes do curso de odontologia e exames clínicos realizados, conforme pode ser verificado nas figuras 9 e 10, constatou-se que todos os cooperados da Futura examinados sentiam dores e precisavam de restaurações odontológicas, $75 \%$ deles precisam de tratamento periodontal e $88 \%$ necessitava de algum tipo de prótese (inferior, superior ou ambas). Além disso, 62,5\% dos cooperados necessitam de tratamentos de exodontia. 
Na cooperativa São Vicente todos os cooperados atendidos sentiam dores e precisavam de tratamento periodontal. Foi constatado que $44,4 \%$ dos cooperados precisam de prótese parcial removível inferior e superior e que $95 \%$ necessita de ao menos um tipo de prótese. Entre os examinados 16,6\% precisam de tratamento de endodontia e 55,5\% de exodontia.

Assim como nas demais cooperativas, na CooperAlfa foi possível constatar que todos sentiam dores e precisavam de tratamentos de dentística (restauração). Em relação aos tratamentos de periodontia 70,6\% dos cooperados necessitavam de algum tipo de prótese (total ou parcial) nos dentes inferiores e superiores. Além disso, 52,94\% dos cooperados necessitam de tratamento de exodontia.

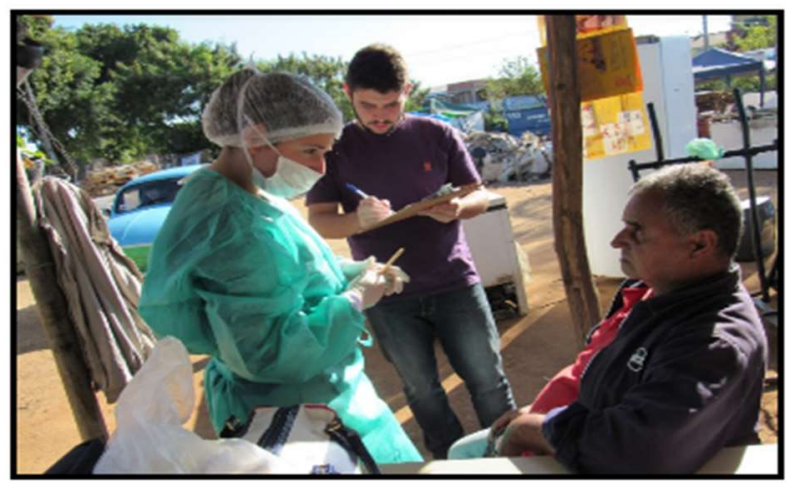

Figura 10: Exame clínico realiza nos cooperados da CooperAlfa.

Após a realização dos exames foram ministradas palestras de educação odontológica que abordaram temas relacionados à: escovação correta, presença de cáries, escovação de próteses, utilização de fio dental e demais conceitos relacionados a higiene bucal. Após as palestras foram distribuídos kits com pastas e escovas de dentes para os cooperados. A Figura 11 mostra uma das palestras sendo realizadas na cooperativa Futura.

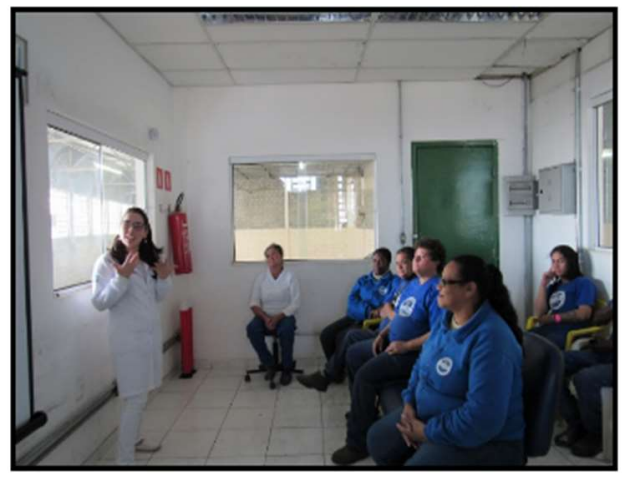

Figura 11: Palestra sendo ministrada na cooperativa Futura.

O SRQ-20 permite avaliar o possível estado de depressão de uma pessoa, no caso, os membros entrevistados. Detectou-se que a porcentagem de pessoas que podem vir a ter sinais de depressão é de 34,5\% nas três cooperativas estudadas. A Figura 12 mostra um gráfico com as respostas positivas ("sim") para as perguntas realizadas no SRQ-20. 
Figura 12 - Perguntas de avaliação do bem-estar dos catadores cooperados e suas porcentagens.

\section{DISCUSSÃO}

A geração de dados sobre a atuação das cooperativas de materiais reutilizáveis e recicláveis nesse projeto contribuiu para a elaboração do Plano Municipal de Gestão Integrada de Resíduos Sólidos, no município de São José dos Campos. Esse mesmo plano aponta as deficiências relacionadas à gestão dos resíduos sólidos e estabelece como uma de suas metas a inclusão social dos catadores e suas cooperativas no sistema de coleta seletiva municipal. A Cooperativa Futura apresenta a melhor infraestrutura, maior volume de material triado e melhores condições de trabalho para seus cooperados, contando com o apoio do Poder Público Municipal para obtenção de resíduos e pagamento de suas despesas. Assim sendo, evidencia relação de forte dependência para a continuidade de seus trabalhos.

A grande maioria dos catadores associados às cooperativas de São José dos Campos, não realizam a separação dos resíduos em sua própria residência. Isso pode estar associado a falta de espaço em suas casas, falta de coleta seletiva na região que habitam ou baixa conscientização ambiental. Todas as cooperativas consideram suas áreas para triagem insuficientes para a realização dos trabalhos. Vale ressaltar que esse dado é uma percepção dos gestores locais, desvinculada de dados ou projetos que a justifique, mas que já se presta a identificar o anseio dessas organizações pela potencialização de suas atividades, no que se refere a investimentos em infraestrutura e estabelecendo novas parcerias.

A cooperativa São Vicente é a mais antiga associação de catadores do município e possui maior área de terreno. No entanto, carece de ser envolvida pelo poder público local nas ações de manejo de resíduos para que as suas atividades sejam realizadas com maior eficiência. É a segunda maior cooperativa do município em relação a triagem de resíduos, renda e número de cooperados associados.

A CooperAlfa evidencia possuir a maior vulnerabilidade entre as cooperativas estudadas, pois, não possui terreno, infraestrutura ou equipamentos para a realização de suas atividades. Seus cooperados obtém renda muito inferior à dos demais cooperados que atuam no território municipal, além disso trabalham em condições precárias.

Assim como os cooperados da região sudeste do Brasil, a maioria dos associados de São José dos Campos declararam-se pardos. A maioria dos cooperados em São José dos Campos são mulheres, com faixa 
etária média de 41 anos. Todas as cooperativas geram renda inferior ao salário mínimo nacional para seus cooperados, ao contrário da situação das cooperativas do estado de São Paulo (IPEA, 2012).

Em relação à saúde bucal e mental dos cooperados, o questionário de avaliação denominado OHIP 14, que condiz com a auto percepção com relação à saúde bucal de cada indivíduo entrevistado, mostrou que poucos indivíduos percebem impactos em suas vidas sociais. Vale ressaltar que esse resultado evidencia que os cooperados possuem baixa percepção de sua região bucal uma vez que todos os cooperados examinados sentem dores e necessitam de algum tipo de tratamento odontológico.

O sistema SRQ-20 utilizado para análise dos dados coletados, indicou que 34,5\% dos indivíduos apresentam sinais de depressão. Além disso, mostrou elevados índices de desconforto e desgosto. Assim sendo, é possível inferir que os cooperados, atuantes no território municipal, carecem também de atenção em relação à saúde mental.

\section{CONCLUSÃO}

Os cooperados apresentam baixo grau de escolaridade e renda, o que condiz com os dados publicados pelo estudo realizado pelo IPEA em 2012 sobre a situação social dos catadores por todo o país. 0 apoio do poder público municipal e de parceiros potencializa as atividades das cooperativas. A atuação de catadores autônomos no município pode ser justificada pela baixa capacidade de inclusão verificado nas cooperativas. Todas as cooperativas declaram necessitar de melhoria na infraestrutura disponível. Os gestores não consideram a área de triagem suficiente para atender à demanda de resíduos e do número de cooperados. Além disso, declaram necessitar de equipamentos para a realização de suas atividades. Segundo os gestores esses são os entraves atuais que inviabilizam a incorporação de novos cooperados.

As cooperativas carecem de capacitação, no que se refere às atividades realizadas e à gestão financeira da organização. A partir da constatação de baixo número de pessoas naturais do município de São José dos Campos nas cooperativas, da baixa escolaridade e da quase inexistência de catadores autônomos incorporados, é possível inferir que as cooperativas existentes oportunizaram a inclusão de pessoas que migraram para São José dos Campos e que, em função do baixo grau de escolaridade, não foram inseridas em outras atividades do mercado de trabalho local.

Os estudos odontológicos realizados mostram a necessidade de atendimento dos cooperados, que estão com dores e vários problemas bucais relacionados à endodontia, exodontia, periodontia e próteses. Uma vez que os cooperados possuem baixa renda, os principais locais de atendimento odontológico acessíveis são as Unidades Básicas de Saúde do município, no entanto, constatou-se que a maioria dos cooperados não possuem cartão do Sistema único de Saúde, o que inviabiliza esse atendimento. 0 diagnóstico sobre o grau de depressão dos cooperados evidencia que os cooperados das três cooperativas carecem de atenção e cuidados pela assistência social e políticas públicas, já que foram observados elevados índices de desconforto e desgosto, que podem influenciar negativamente o dia a dia dessas pessoas. 


\section{REFERÊNCIAS}

ABRELPE. Associação Brasileira de Empresas de Limpeza Pública e Resíduos Especiais. Panorama dos resíduos sólidos no Brasil. São Paulo: ABRELPE, 2013.

BARBIERI, C. H.; RAPOPORT, A.. Avaliação da qualidade de vida dos pacientes reabilitados com próteses implanto-muco suportadas versus próteses totais convencionais. Revista Brasileira Cirurgia Cabeça Pescoço, v.38, n.2, 2009.

CEMPRE. Centro de Estágio e Emprego. Compromisso Empresarial para a Reciclagem. Cempre Review, 2013.

GOUVEA, N.. Resíduos sólidos urbanos: impactos socioambientais e perspectiva de manejo sustentável com inclusão social. Rio de Janeiro: 2008.
IBGE. Instituto Brasileiro de Geografia e Estatística. Sinopse do censo demográfico. São Paulo: IBGE, 2010.

IPEA. Instituto de Pesquisa Econômica Aplicada. Diagnóstico sobre Catadores de Resíduos Sólidos. Brasília: IPEA, 2012.

JACARANDÁ, E. M. F.. Sofrimento Mental e Satisfação no Trabalho: um estudo dos professores das escolas inclusivas estaduais de ensino fundamental em Porto Velho. Brasília: 2008.

SNIS. Sistema Nacional de Informação sobre Saneamento. Diagnóstico do manejo de resíduos sólidos urbanos. Brasília: 2013.

SNIS. Sistema Nacional de Informação sobre Saneamento. Diagnóstico do manejo de resíduos sólidos urbanos. Brasília: 2015. 